\title{
Economics of theileriosis control in Zambia
}

\author{
L. D'Haese', K. Penne' ${ }^{2}$ and R. Elyn ${ }^{2}$ \\ 1 University of Antwerp, Institute for Development Policy and Management, Belgium \\ 2 Assistance to the Veterinary Service in Zambia-South, Zambia
}

Summary For an economic analysis of theileriosis control, we adopted the total economic cost (TEC) method, which calculates the sum of output losses from tick damage, theileriosis mortality and morbidity, and expenditures for treatment or prevention of the disease. At farm level, the TEC can be minimized by a specific combination of vector control and/or immunization and an acceptable level of losses. Expenditures for vector control include acaricides, construction of dipping or spraying facilities and their maintenance, and variable costs such as those for water and labour. Economics of vector control depend on the herd size and the method of application of the acaricide. Morbidity, mortality and tick damage losses are effectively reduced by correct and intensive vector control programmes. Expenditures for vector control are estimated at US\$ 8.43, 13.62 and 21.09 per animal per year for plunge dipping, hand spraying and pour-on, respectively. Immunization costs comprise production of parasite stabilates, storage and application, delivery and treatment. At US\$ 9.5 per animal, immunization limits losses caused by Theileria parva, but ticks still may reduce the productivity of the animals. Expenditures for treatment after natural infection involve drugs, transport, veterinary fees and farm labour costs. Treatment has a moderate success rate, hence both morbidity and mortality remain important factors. Equally, it does not affect the vector, which may continue to reduce overall productivity of cattle. Expenditures for treatment range between US\$ 9.04 and US\$27.31 per animal. To compare different TECs in relation to different control strategies, assumptions have to be made on disease occurrence, case fatality, value and productivity of the cattle, reductions in productivity due to morbidity and number of animals under a specific control regime. Calculations based on data from Southern Province, Zambia show that large-scale immunization reduces the TEC by $90 \%$ compared to no intervention. Treatment, which is the second-best option, reduces the TEC by $60 \%$.

keywords theileriosis control; Zambia; veterinary economics

correspondence Professor L. D’Haese, Institute for Development Policy and Management, University of Antwerp, Belgium

\section{Introduction}

Theileriosis, caused by the protozoon Theileria parva, is a cattle disease transmitted by the brown ear-tick Rhipicephalus appendiculatus. It is widespread in 11 countries in eastern, central and southern Africa (Perry et al. 1991). In Zambia it is usually referred to as East Coast Fever (ECF) or Corridor Disease (Nambota 1991). Traditionally, Corridor Disease refers to the disease caused by T. parva transferred from buffalo (Syncerus caffer) to cattle (Grootenhuis 1989), but in Southern Province, Zambia, it is commonly used for any form of ECF. The disease can be relatively mild, causing low mortality, restricted to calves only, but full-scale epidemics affecting all age groups do occur (Berkvens 1991). Different breeds of cattle react differently to ECF challenge, with Zebu cattle showing more resistance than taurine breeds against both the parasite (Guilbride \& Opwata 1963) and the vector (Jongejan et al. 1989; Fivaz \& Norval 1990).

Other tick-borne diseases such as anaplasmosis, babesiosis and cowdriosis in Southern Province cause low mortality: 0.1, 0.01 and $0.02 \%$, respectively, in 1996 (Animal Production and Health Sub-Program 1996). Moorhouse and Snacken (1984) reported that babesiosis (Babesia bigemina) and anaplasmosis are enzootically unstable and that their inoculation rates are unlikely to be of economic importance. Jongejan et al. (1988) reported that tick control has little effect on the control of anaplasmosis due to the presence of other vectors. It appeared that none of these other tick-borne diseases caused significant problems once tick control was abandoned following immunization against ECF in Eastern Province 
L. D'Haese et al. Epidemiology and control of bovine theileriosis

(Berkvens 1991). Hence this discussion will mainly focus on ECF-control.

At farm level, ECF is traditionally controlled by vector control, by immunization against the parasite or by treating natural infections. Ticks can be controlled with acaricides by plunge-dipping, where animals plunging into and swim through dipping tanks containing an aqueous emulsion, suspension or solution of acaricide. Complete or almost complete immersion of cattle during dipping ensures adequate exposure of ticks to acaricide. The frequency of treatment depends on the acaricide used (Norval et al. 1992b).

Other widely used methods of acaricide application involve hand or engine-powered spraying. These methods of spraying seldom achieve complete wetting of the animal, usually resulting in poor tick control (Norval et al. 1992b). Excess acaricide solution drips off the animal and is not recycled as in dipping tanks, where cattle are held in draining pens after treatment. Nevertheless, if used correctly, spraying offers small-scale farmers a means to control ticks. The spray race is very common at commercial dairy farms (Norval et al. 1992b) but virtually absent in the traditional sector.

To control ticks at specific body sites only, such as the ears or the perineum, tick grease, an acaricide in a petroleum jelly base, is applied with a brush. More recently 'spot-on' and 'pour-on' acaricides have become available. These formulations include propellants that spread readily over the surface of skin and hair (Norval et al. 1992b). Acaricides are thus applied to limited areas of the body, from where they spread to much larger areas. Spot-ons are normally used to control ticks on a particular body part such as the head, while pour-ons are applied in a strip down the length of the back to give tick control over the entire body.

Four chemical products are known to have an effect against Theileria parva infections: menoctone, parvaquone, buparvaquone and halofuginone. Menoctone has not been developed as a commercial product because its synthesis is too expensive. Parvaquone has been commercialized as Clexon ${ }_{s}$ and more recently as Parvexon, whereas buparvaquone is available as Butalex, and halofuginone is sold as Terit. In vivo, buparvaquone is more effective than parvaquone against T. parva infections (McHardy et al. 1985) but in Zambia Butalex is 5 times more expensive than Parvexon. Terit does not work in the early stages of the disease (Norval et al. 1992b) and it is no longer commercially available in Zambia. Hence, we only calculated the TEC for treatment with buparvaquone

(Butalex) and parvaquone (Parvexon).

Efficacy of chemotherapy depends on early and fast diagnosis. Treatment should be given in the early stages of clinical disease; after the onset of respiratory symptoms none of the chemotherapeutic agents is effective any more (Norval et al. 1992b). Recovered animals can remain carriers of the parasite (Maritim et al. 1988) and it is suspected that this occurs more frequently after parvaquone treatment (Dolan 1986a,b) than when buparvaquone (Mutugi et al. 1988) was used. The current immunization used for ECF is the 'Infection and Treatment method' (Radley 1981) whereby a titrated sporozoite stabilate of infected ticks is injected simultaneously with a $20-\mathrm{mg} / \mathrm{kg}$ b.w. dose of long-acting tetracyclines. Selection of the immunizing stock(s) of T. parva should ensure that cattle are immunized against subsequent field challenges with all T. parva stocks in the area.

\section{Materials and methods}

Theileriosis results in inevitable costs for cattle keepers, either by losses in productivity or by expenditures for disease and/or vector control. Cattle owners will try to adopt a strategy which minimizes the overall costs. It would not be economical to maximize output at any cost. We used the total economic cost (TEC) methodology proposed by McInerney et al. (1992), which calculates the sum of output losses due to theileriosis mortality and morbidity, tick damage, plus the expenditures for treatment or preventive measures. At the optimal level of control marginal cost equals marginal savings in production losses, thus minimizing the TEC of the disease.

In scrutinizing the costs of the different control strategies, i.e. no intervention, treatment, vector control and immunization, we distinguished between productivity losses (morbidity, mortality and productivity losses due to the presence of ticks) and expenditures (fixed costs and variable costs). Productivity losses were derived from literature and expert opinions, expenditures were quantified based on data gathered in Southern Province, Zambia. Drugs and acaricides were used as recommended by the manufacturer, even when these doses had been reported to be insufficient.

The TEC for the available control strategies are estimated as a function of disease occurrence, based on the herd-projection model developed within the ASVEZA (Assistance to the Veterinary Service in Zambia) project (Penne \& D'Haese 1997). This model calculates the impact of different control strategies over the next 30 years and integrates chemotherapy as an alternative, which so far was not included in similar models. The model provides a number of economic parameters (such as TEC, benefit/cost ratio, Net Present Value of cattle farm) and graphs (herd size, animal production, income and annual costs) for the evaluation of different control strategies. It is a drawback that strategies cannot be combined (e.g. 50\% dipping combined with immunization). The deterministic nature of the model leaves little room for evaluation of risk and variability in the epidemiological environment, which are typically stochastic. In our calculations, expenditures for each of the preventive and curative actions was estimated at farm level. The exchange rate from 
L. D'Haese et al. Epidemiology and control of bovine theileriosis

Zambian Kwacha to US dollar is $1300 \mathrm{ZK}=1$ US\$. Prices indicated are those of September 1997.

\section{Results and discussion}

\section{Identification of losses and expenditures}

An overview of the different components to calculate the TEC for different control strategies is given in Appendix 1. The model evaluates the TEC at farm level; therefore certain costs such as environmental costs, opportunity cost for foreign exchange and research are not included. These should be included in analyses at national level. Some authors have reported traditional ways of ECF-treatment (Okamoto 1993) and tick control (Mwangala 1997) in Zambia. These methods are largely based on experiences from traditional herb doctors and have not yet been evaluated scientifically. Therefore these methods could not be taken into account.

\section{No intervention}

Morbidity and mortality losses follow the occurrence of tickborne diseases. If case fatality rates (defined as number of fatal cases divided by total number of cases times 100, during a given period) are high, animals die quickly and morbidity losses are negligible. An indirect, but significant, morbidity loss may be related to the drying-off of cows after loosing their calves (Van Doorslaer 1996). If the case fatality is low, more animals survive and morbidity losses will be more prominent. Ticks, in Southern Province mainly Amblyomma, Hyalomma, Boophilus and Rhipicephalus species (Speybroeck 1994) affect productivity. The entire feeding period of a single engorged female Amblyomma spp. or Rhipicephalus spp. lowers milk production by $7 \mathrm{~g}$ (Norval et al. 1990a,b). Life weight gain is reduced by, respectively, $4 \mathrm{~g}$, $10 \mathrm{~g}$ and 41-61 g per engorged adult female of $R$. appendiculatus, Amblyomma hebraeum or Amblyomma variegatum (Norval et al. 1988, 1989; Pegram et al. 1989). Hides infested by ticks have lower commercial value. In this scenario, without intervention, there are no expenditures.

\section{Treatment}

According to Musisi et al. reported by McHardy (1988), a single intramuscular dose of Butalex(c) $2.5 \mathrm{mg} / \mathrm{kg}$ in 68 cattle with theileriosis in Zambia achieved a cure rate of $91 \%$. Treatment by the ASVEZA-project of 48 confirmed theileriosis cases with the same dose achieved a cure rate of $85 \%$ in Nteme (Monze district) in 1994. Thus treatment leads to a drop in case fatality from $95 \%$ (no intervention) to less than $20 \%$ (after treatment). Consequently, losses due to mortality decrease by the same factor. Losses due to morbidity will increase because more animals survive clinical disease. Mukhebi et al. (1992) estimated morbidity losses in animals surviving clinical theileriosis at $25 \%$ loss in milk production in affected cows, $5 \%$ and $10 \%$ loss in beef production in recovered calves and preadult animals, respectively, $3 \%$ reduction in draft capacity and $12.5 \%$ reduction in manure production. These losses are assumptions by experts, and more accurate data are not available. The reproductive function of T. parva infected animals is also affected (Rumberia et al. 1993). Productivity losses caused by tick loads remain in this scenario, where treatment is limited to ECF.

There are no fixed expenditures at farm level. At macro level, a drug delivery system has to be maintained involving research, infrastructure, production, storage, transport, and import. At farm level, expenditures for treatment comprise the costs for the theilericide plus field delivery. The former is determined by product price, dosage and body weight (b.w.). Delivery cost is the sum of transport costs, professional fees for a veterinarian or a veterinary assistant and their equipment and farm labour cost to round up and restrain the animals. These expenditures vary according to the drug used. Transport cost, professional fees and farm labour cost are higher when Parvexon is used, because it requires two injections as opposed to only one with Butalex. However, professional fees, in relation to the former product, are only $50 \%$ higher because an assistant rather than a veterinarian can administer the second injection, and since an assistant lives nearby and travels by motorbike rather than car, transport costs are only $20 \%$ higher. The expenditures related to these interventions are given in Table 1. Per treatment they vary from US\$ 9.04-27.31 depending on the weight of the animal.

\section{Vector control}

When correctly implemented, vector control effectively reduces losses due to morbidity, mortality and tick loads (Pegram et al. 1991; Minjauw et al. 1997). In Zambia's

Table I Treatment

\begin{tabular}{lcc}
\hline & Parvexon & Butalex \\
\hline Price $($ US \$/ml) & 0.30 & 1.46 \\
Dose (ml/kg LW) & 0.15 & 0.05 \\
Transport cost (US \$) & 2.31 & 1.92 \\
Professional fee (US \$) & 4.62 & 3.08 \\
Farm labour cost (US \$) & 0.77 & 0.38 \\
Treatment cost (in US \$) & & \\
$\quad$ Calf $50 \mathrm{~kg}$ & 9.94 & 9.04 \\
$\quad$ Immature $125 \mathrm{~kg}$ & 13.32 & 14.52 \\
$\quad$ Adult 300 kg & 21.19 & 27.31 \\
\hline
\end{tabular}

(Source: ASVEZA, unpublished). 


\section{D'Haese et al. Epidemiology and control of bovine theileriosis}

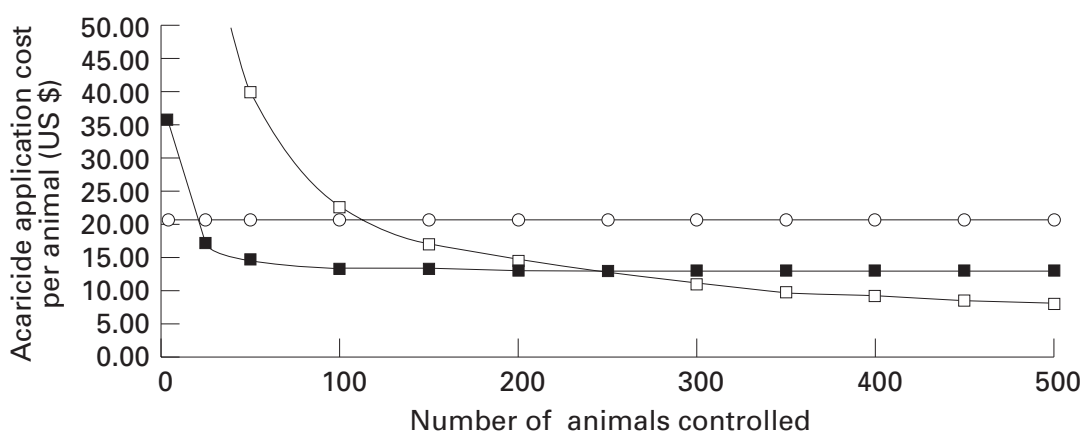

Figure I Acaricide application cost per animal per year (in US\$), method of application as a function of the number of animals controlled. $\square$ Dipping; $\square$ Spraying; $\bigcirc$ Pour-on. traditional sector acaricides are applied by plunge dipping tank, by hand spraying and as pour-ons.

\section{Plunge dipping tank}

In the following discussion a 'head dipped' should be understood as one bovine dipped once. 'Animal dipped' refers to a bovine dipped at regular intervals, as recommended by the manufacturer, for a period of one year. Initially, the cost is calculated for a dipping tank that caters for 500 animals; then the calculations are generalized for a variable number of cattle. The cut-offs between different acaricide applications are determined as a function of herd size. For our case study in Southern Province, this is assumed to be 25 cattle. Farmers are reluctant to collaborate in vector control, mainly due to lack of trust and interest in the absence of the disease for longer periods. The price per animal dipped is based on 10year experience with a dipping tank in Monze district, Southern Province, Zambia (Penne et al. 1996). Expenditures are grouped into four components: dipping tank construction (fixed), annual dipping tank maintenance (fixed), acaricides (variable) and additional costs such as those for water, labour, etc. (variable).

The total construction cost is US\$ 5000. Assuming a linear (simplification) depreciation time of 10 years, the annual cost is US\$ 500. Annual maintenance costs comprise repairs, recharging the dipping tank and daily management, and are calculated at US\$ 720. Total annual costs for construction and maintenance are divided by the number of animals dipped during that year to get the cost per animal dipped per year, i.e. for 500 animals it amounts to US\$2.44. In case of a herd of only 25 animals, this amounts to US\$ 48.8 per animal dipped - an unattractive option for small herds (Figure 1).

The most common acaricides used in Zambia and the number of treatments needed per year with concentrations for charging and replenishment, as specified by the manufacturer, are given in Table 2 and 3, respectively. Costs for

\begin{tabular}{lll}
\hline Commercial name & Active ingredient & Chemical category \\
\hline Grenade & Cyhalothrin $5 \%$ & Synthetic pyrethroid \\
Supadip & Chlorfenviphos $110 \%$ & $\begin{array}{l}\text { Organophosphorus compound } \\
\text { Triatix/Milbitraz }\end{array}$ \\
Decatix & Amitraz $12.5 \%$ & $\begin{array}{l}\text { Formamidine } \\
\text { Deltamethrin } 5 \%\end{array}$ \\
& & Synthetic pyrethroid \\
\hline
\end{tabular}

(Source: ASVEZA, unpublished).

Table 2 Common acaricides used in Zambia

\begin{tabular}{lrrrr}
\hline & Grenade & Supadip & Triatix & Decatix \\
\hline Number of immersions per year & \multicolumn{1}{c}{30} & \multicolumn{1}{c}{64} & \multicolumn{1}{c}{52} & \multicolumn{1}{c}{40} \\
Price/l & 36.62 & 69.23 & 12.11 & 69.45 \\
Cost initial fill & 732.31 & 503.85 & 484.62 & 1042.31 \\
Initial fill/head dipped & 0.05 & 0.02 & 0.02 & 0.05 \\
Cost replenishment & 0.13 & 0.16 & 0.10 & 0.16 \\
Cost per head dipped & 0.18 & 0.17 & 0.12 & 0.21 \\
Annual cost per animal dipped & 5.39 & 10.76 & 6.21 & 8.34 \\
& & & & \\
\hline
\end{tabular}

" based on 500 heads, dipped in Zambia in 1997, following manufacturers' instructions in order to get full tick control (Source: ASVEZA, unpublished).

Table 3 Acaricides for plunge dip 


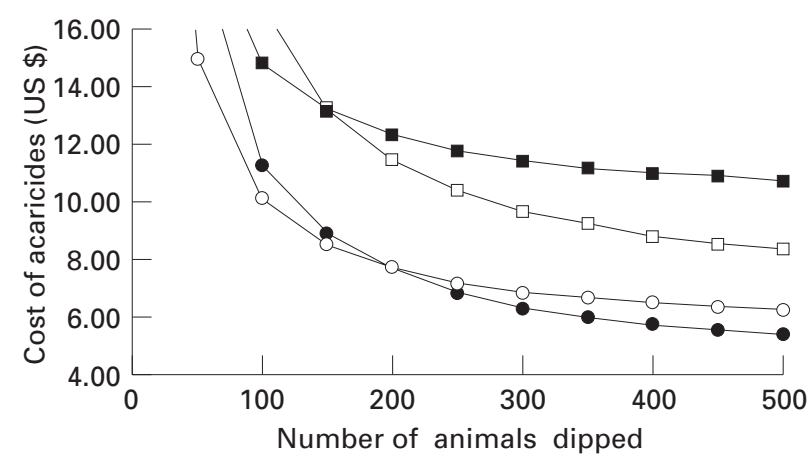

Figure 2 Cost of different acaricides (in US \$) as a function of the number of animals dipped. Grenade; $\square$ Supadip; $\square$ Triatix; $\bigcirc$ Decatix.

acaricides are calculated for a herd size of 500 animals. Water ( $2.5 \mathrm{l} / \mathrm{head})$ and farm labour, the variable requirements, are estimated at 0.02 US\$ per head dipped. As these are obviously related to the frequency of treatments, Triatix would incur costs of US\$ 0.60 per animal dipped and Grenade US\$1.04. The total annual expenditure for dipping 500 animals with Grenade is estimated at US\$ 8.43 per animal. Expenditures for plunge dipping are plotted in Figure 2 in relation to herd size and product used.

\section{Hand spraying}

The only fixed requirements are two knapsack sprayers and a crush-pen. A knapsack sprayer lasts on average four years and costs US\$ 75. With 50 animals in a herd, the average cost is US\$ 0.75 per animal per year. The annual cost for the depreciation and maintenance of a crush-pen is US\$ 80 or US\$ 1.6 US per animal. The annual cost for acaricides is calculated in Table 4. Labour at 25 animals per person per day, and water at $10 \mathrm{l}$ per animal make up the variable costs for hand spraying, amounting to US\$ 0.095 per head. Spraying with Grenade, the cheapest treatment (Table 4), calculated for a herd-size of 50 animals, costs US\$ 13.62 per animal/year.

\section{Pour-on}

Spoton, with deltamethrin as the active ingredient at a concentration of $10 \mathrm{~g} / \mathrm{l}$, is used at a concentration of $10 \mathrm{ml}$ per

Table 4 Acaricides for spraying

\begin{tabular}{lcl}
\hline & Price (US\$) & US\$ per year \\
\hline Triatix HCMV & $0.77 / 10 \mathrm{~g}$ & 40.00 \\
Grenade & $36.6 / 1$ & 12.21 \\
Supadip & $69.2 / 1$ & 21.46 \\
Decatix & $69.5 / 1$ & 27.78 \\
\hline
\end{tabular}

$10 \mathrm{l}$ water used per animal to obtain complete wetting (Source: ASVEZA, unpublished). $100-\mathrm{kg}$ body weight. To maintain constant protection it must be applied at four-weekly intervals (13 times per year). Spoton costs US\$ 12.9 per $200 \mathrm{ml}$. Farm labour is estimated at US\$ 0.01 per animal per application. The annual application cost thus is US\$21.09 for an animal with an average b.w. of $250 \mathrm{~kg}$.

\section{Cost of different applications in function of the herd size}

The costs of all acaricide applications, except for pour-on treatments which involve no fixed costs, are scale dependent. Dipping is most dependent on herd size is because of costs for construction, maintenance and initial charging of the tank. Figure 1 plots the costs as a function of the herd size with the most economical acaricide application given for a herd of 5, 25 and 500 cattle, respectively. In case of less than 5 animals, pour-on seems to be the most cost-effective acaricide application, with costing just over US\$20 per animal per year. If 25 animals have to be protected, spraying with Grenade is recommended at US\$ 17.20 per animal per year. The most economical vector control for a large herd of 500 cattle appears to be dipping with Grenade at US\$ 8.43 per animal per year.

However, in the traditional sector maximum efficiency in vector control is hard to achieve due to the above mentioned difficulties in implementing it on a wider scale, and for the purpose of controlling ECF it is practically impossible in Eastern Province (Berkvens 1991). Kadohira et al. (1996) reported losses from Corridor disease in Central Province, where $90 \%$ of farmers lost more than half of their cattle during the $1992-93$ outbreaks although $40 \%$ of them carried out regular tick control.

\section{Immunization}

Immunization reduces mortality significantly. Berkvens et al. (1988) reported $33 \%$ mortality in nonimmunized calves as opposed to $5.5 \%$ in immunized calves in Chipata district. After 5 years of immunization (39 164 calves) these figures were reduced to $19.1 \%$ and $2.6 \%$ for nonimmunized and immunized calves, respectively (D'Haese \& Thys 1993). In terms of reproduction, immunization against theileriosis has no long-term adverse effect on the cyclical status (Rumberia et al. 1994), nor on the calving rates (Dolan \& Mutugi 1989). The same observation was made (Lynen et al. 1991) after large scale immunization in Eastern Province. Losses due to tick loads are the same as in the case of no intervention. Calculations on the costs for immunization (Table 5) range from US\$ 2.37-25 per animal (Radley 1981; Irvin 1984; Kiltz 1984; Mukhebi et al. 1990; Mukhebi et al. 1995; Elyn 1996; Penne et al. 1996). Expenditures for immunization reported here are based on figures obtained by the ASVEZA project in 


\section{D'Haese et al. Epidemiology and control of bovine theileriosis}

Table 5 Cost of immunization (in US\$): review of literature

\begin{tabular}{lllll}
\hline Author & Year & Cost/animal & Place & Remarks \\
\hline Radley & 1981 & 2.51 & Hypothetical & \\
Kiltz & 1984 & 20 & Burundi & 0.01 for stabilate \\
Irvin & 1984 & $5-6$ & Malawi & 0.1 for stabilate \\
Mukhebi et al. & 1990 & 2.37 & Kenya & 0.89 for stabilate \\
Mukhebi et al. & 1995 & 25 & Coast Province Kenya & Pilot immunization trial \\
Elyn & 1996 & 9.79 & Eastern Province Zambia & Mass immunization campaign \\
Penne et al. & 1996 & 8.67 & Southern Province Zambia & Hypothetical, based on Experience Eastern Province \\
\hline
\end{tabular}

Eastern Province since 1987 (Elyn 1996).

For both stabilate production and field operations, investments and operational costs were identified, quantified and estimated at replacement price. Capital investments for stabilate production consist of the laboratory buildings, stables and basic equipment. A depreciation cost for these items is included. Operating costs for stabilate production cover laboratory equipment and consumables, chemicals, experimental animals and personnel. Field immunization costs comprise operational expenditures such as transport, liquid nitrogen and tetracyclines. For Southern Province, with 15000 animals in the annual immunization programme and

Table 6 Immunization cost calculated for Eastern Province, Zambia

\begin{tabular}{llrr}
\hline & US $\$$ & ZK & $\%$ of Total \\
\hline Cost stabilate & 1.80 & 2335 & 19 \\
Cost field & 7.70 & 1000 & 81 \\
Delivery & & 8 & \\
$\quad$ Cars & 3.00 & 3900 & 32 \\
$\quad$ Motorbikes & 0.93 & 1210 & 10 \\
$\quad$ Terramycine & 2.25 & 2925 & 24 \\
$\quad$ Salaries & 0.73 & 952 & 8 \\
$\quad$ Others & 0.78 & 1020 & 8 \\
Total cost per dose & 9.5 & 12343 & 100 \\
\hline
\end{tabular}

(Source: Elyn 1996). an average b.w. of $250 \mathrm{~kg}$ per animal (i.e. immunizing all animals) immunization would cost US\$ 9.5 per animal. A breakdown is given in Table 6 .

\section{Southern Province case study}

We used a herd projection model (Penne \& D’Haese 1997) to calculate the TEC for the different strategies based on the above identified losses and on the calculated expenditures. The costs are calculated for a farm with 25 cattle in Southern Province, Zambia. A full list of assumptions, for a traditional farm in Southern Province, is given in Penne \& D'Haese (1997). An average theileriosis occurrence of $15 \%$ with $20 \%$ of cases being subclinical is assumed. Plunge dipping and pour-ons result in a higher TEC than no intervention, i.e. US\$ 59.56, 23.55 and 21.47 per animal per year, respectively. At US\$ 2.36 per animal per year the TEC for immunization is minimal when all animals are immunized (Table 7). Disease occurrence is an important factor in the estimation of the TEC: if the disease did not occur, expenditures for prevention would be uneconomical. The TEC for some strategies (treatment, immunization of calves only) depends more on disease occurrence than other strategies (total immunization, vector control).

Figure 3 gives the TEC per animal per year as a function of disease occurrence: The most economic strategy, when disease occurrence is between $1.5 \%$ and $5 \%$ (point b), is treat-

\begin{tabular}{lclcc}
\hline & Mortality & Morbidity & Expenditures & TEC/Animal \\
\hline No intervention & 21.46 & 0.01 & 0.00 & 21.47 \\
Plunge-dipping & 0.20 & 0.00 & 59.36 & 59.56 \\
Spraying & 2.01 & 0.00 & 16.84 & 18.85 \\
Pour-on & 2.01 & 0.00 & 21.54 & 23.55 \\
Immunization calves only & 8.76 & 0.00 & 1.17 & 9.93 \\
Total immunization & 0.20 & 0.00 & 2.16 & 2.36 \\
Butalex & 4.13 & 0.40 & 2.54 & 7.06 \\
Parvexon & 4.13 & 0.40 & 2.04 & 6.57 \\
& & & & \\
\hline
\end{tabular}

Table 7 TEC per animal per year (in US\$)

(Source: Results from TBD-Model, ASVEZA unpublished). 
L. D'Haese et al. Epidemiology and control of bovine theileriosis

Figure 3 TEC as a function of control scenario and disease occurrence. $\bigcirc$ No intervention; …... Spraying; ------ Pour-on; $\square$ Immunization of calves only; $\boldsymbol{B}$ Blanket immunization; Parvexon.

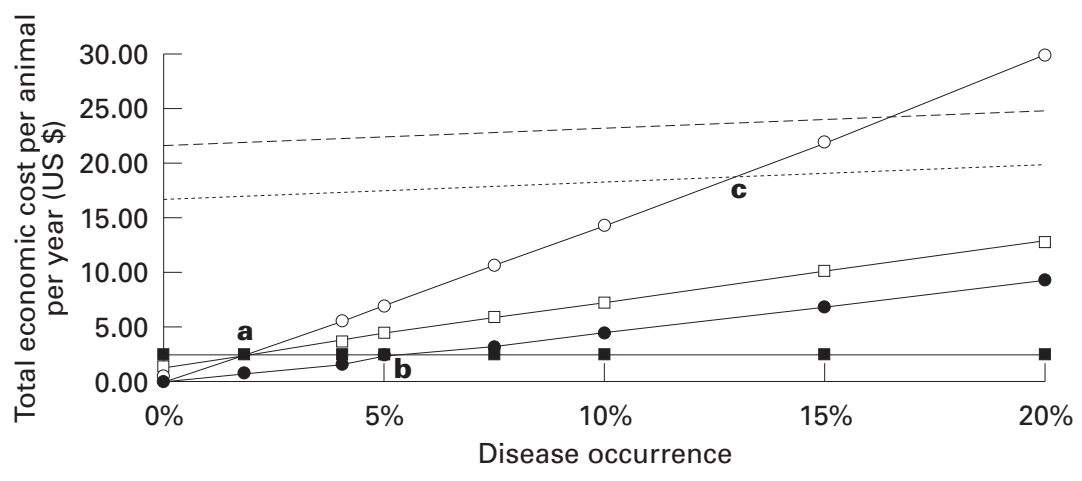

ment with Parvexon after natural infection; once incidence rises above $5 \%$, the best strategy appears to be total immunization. Immunization of calves only is not desirable because adults will continue dying and incur mortality costs in excess of the cost to immunize them. At incidences levels below $1.5 \%$ it is cheaper to have no intervention (point a) than immunization. Spraying results in a high TEC, and only when disease occurrence exceeds $13 \%$ (point c), it is better to spray than to let the animals die.

\section{Comparison of the Southern Province case study with other studies}

Compared to acaricide applications in production systems with indigenous cattle, the scenario of immunization allows for a reduction of the TEC with 20-67\% (Mukhebi 1996). However, immunization of calves only reduces TEC by $54 \%$ and $47 \%$ compared to no intervention and spraying, respectively. But the TEC increases by $51 \%$ compared to treatment with Parvexon. Total immunization leads to reductions of $89 \%, 87 \%$ and $36 \%$ compared to no intervention, spraying and treatment with Parvexon, respectively.

\section{Conclusions}

Losses due to theileriosis in all age groups indicate an epidemic. This leads to higher losses in productivity and hence will affect TEC in comparison with a more endemic situation in which only young animals are affected. Theileriosis incidence of less than 5\% is not likely in Southern Province except during exceptional droughts. When theileriosis incidence is $15 \%$, i.e. the average situation in Southern Province, the TEC is reduced by almost $90 \%$ if total immunization is chosen rather than a policy of no intervention.

Immunization of calves only, i.e. leaving adults unprotected during a transition period of a few years, results in lower expenditures due to less terramycin use (b.w. dependant), but this gain is completely eliminated by losses in the adult group during the transitional phase. As shown in Figure 3, whatever the percentage of disease occurrence, immunizing all animals always results in a lower TEC than immunizing calves only. Total immunization, even though the most economic choice, has considerable practical constraints if it has to be implemented on a large scale. There are 560000 cattle in the theileriosis-affected area of Southern Province. It is impossible to immunize all of them in one campaign. Farmers' willingness to pay for the immunization is unknown, but experience from Eastern Province shows that attendance after several years of immunization campaigns free of charge could be as low as $10-15 \%$ during the first year of implementation of payment by the farmers. With a similar attendance for Southern Province, the number of animals to be immunized in the first campaign could be around 50000-75000. Higher attendance could result in logistical constraints, especially during the first immunization campaign. Should stabilate production be insufficient, treatment would be the secondbest intervention strategy within the limits of disease occurrence reported for Southern Province.

\section{References}

Animal Production and Health Sub-Program (1996) Annual Report Southern Province. Department of Research and Specialised Services, Ministry of Agriculture Food and Fisheries, Republic of Zambia, p. 31.

Berkvens DL (1991) Re-assessment of tick control after immunisation against East Coast fever in the Eastern Province of Zambia. Annales de la Societé Belge de Médecine Tropicale 71 (Suppl.), 87-94.

Berkvens DL, Geysen DM \& Lynen GM (1988) East Coast fever immunisation in the Eastern Province of Zambia. In Proceedings of a Workshop on East Coast Fever Immunisation, Lilongwe, Malawi 20-22 September 1988 (ed. TT Dolan), pp. 83-86.

D'Haese LD \& Thys E (1993) Evaluatie van de impakt van het 'Belgian Animal Disease Control Project' (Chipata - Zambia). University of Antwerpen, 27 April 1993, 34p.

Dolan TT (1986a) Chemotherapy of East Coast fever: the long-term weight changes, carrier state and disease manifestations of Parvexon-treated cattle. Journal of Comparative Pathology 96, 137-145. 
L. D'Haese et al. Epidemiology and control of bovine theileriosis

Dolan TT (1986b) Chemotherapy of East Coast Fever. Acta Tropica 43, 165-173.

Dolan TT \& Mutugi JJ (1989) The fertility of Boran heifers immunised against buffalo-derived Theileria parva. In Proceedings of a Workshop on East Coast Fever Immunisation, Lilongwe, Malawi 20-22 September 1988 (ed. TT Dolan), pp. 68-70.

Elyn RND (1996) Cost analysis of immunisation for ECF by the infection and treatment method in Eastern Province of Zambia. Internal ASVEZA publication, pp. 18.

Fivaz BH \& Norval RAI (1990) Immunity of the ox to the brown ear tick Rhipicephalus appendiculatus (neumann). Experimental and Applied Acarology 8, 51-63.

Grootenhuis JG (1989) The role of wildlife in the epidemiology of cattle Theileriosis. In Proceedings of a Workshop on East Coast Fever Immunisation, Lilongwe, Malawi 20-22 September 1988 (ed. TT Dolan), pp. 129-136.

Guilbride PDL \& Opwata B (1963) Observations on the resistance of Jersey/Nganda calves to East coast fever (Theileria parva). Bulletin of Epizootic Diseases of Africa 11, 289-298.

Irvin AD, ed. (1984) Immunisation against Theileriosis in Africa. International Laboratory for Research on Animal Diseases, Nairobi, pp. 1-167.

Jongejan F, Perry BD, Moorhouse PDS, Mussisi FL, Pegram RG \& Snacken M (1988) Epidemiology of Bovine Babesiosis and Anaplasmosis in Zambia. Tropical Animal Health Prod. 20, 234-242.

Jongejan F, Pegram RG, Zivkovic EJ et al. (1989) Monitoring of naturally acquired and artificially induced immunity to Amblyomma variegatum and Rhipicephalus appendiculatus ticks under field and laboratory conditions. Experimental and Applied Acarology 7, 181-199.

Kadohira M, Samui KL \& Mwalamgwa JED (1996) The Health and Productivity of Traditionally Managed Cattle in Lusaka Province, Zambia: Results of a questionnaire Survey. Zambian Journal of Veterinary Science 1, 9-16.

Kiltz HH (1984) Theileriosis in Burundi. In Immunisation Against Theileriosis in Africa (ed. AD Irvin) International Laboratory for Research on Animal Diseases, Nairobi, pp. 12-15.

Lynen GM, Makala LHC \& Pas WM (1991) East Coast fever immunisation in Eastern Province, Zambia. In Ticks and Tick-borne disease control, proceedings of a joint OAU, FAO and ILRAD workshop held in Kampala, Uganda, 12-14 September 1991 (ed. TT Dolan), pp. 16-21.

Maritim AC, Kariuki DP, Young AS \& Mutugi JJ (1988) The importance of the Carrier State of Theileria parva in the Epidemiology of Theileriosis and its Control by Immunisation. In Proceedings of a Workshop on East Coast Fever Immunisation, Lilongwe, Malawi 20-22 September 1988 (ed. TT Dolan), pp. 121-120.

McHardy N (1988) Buparvaquone, the new antitheilerial: a review of its efficacy and safety. In Proceedings of a Workshop on East Coast Fever Immunisation, Lilongwe, Malawi 20-22 September 1988 (ed. TT Dolan), pp. 158-165.

McHardy N, Wekesa LS, Hudson AT \& Randall AW (1985) Antitheilerial activity of BW $720 \mathrm{C}$ (buparvaquone): a comparison with parvaquone. Research in Veterinary Science 39, 29-33.

McInerney JP, Howe KS \& Schepers JA (1992) A framework for the economic analysis of disease in farm livestock. Preventive
Veterinary Medicine 13, 137-154.

Minjauw B, Otte J, James AD, de Castro JJ \& Sinyangwe P (1997) Effect of different East Coast Fever control strategies on fertility, milk production and weight gain of Sanga cattle in the Central Province of Zambia. Experimental and Applied Acarology 21, 715-730.

Moorhouse PDS \& Snacken M (1984) Report of a Baseline Study of Selected Diseases of Cattle Carried Out at Macha Development Area from October 1983 - January 1984. Central Veterinary Research Institute, Balmoral, pp. 17.

Mukhebi AW, Kariuki DP, Mussukuya E et al. (1995) Assessing the economic impact of immunisation against East Coast fever: a case study in Coast Province, Kenya. Veterinary Record 137, 17-22.

Mukhebi AW, Morzaria SP, Perry BD, Dolan TT \& Norval RAI (1990) Cost Analysis of immunisation for East Coast fever by the infection and treatment method. Preventive Veterinary Medicine 9, 207-219.

Mukhebi AW, Perry BD \& Kruska R (1992) Estimated economics of Theileriosis control in Africa. Preventive Veterinary Medicine 12, 73-85.

Mukhebi AW (1996) Assessing economic impact of tick-borne diseases and their control: the case of Theileriosis immunisation. FAO Workshop, Harare, March 1996, pp. 147-155.

Mutugi JJ, Young AS, Maritim AC et al. (1988) Immunisation of cattle against Theileriosis using varying doses of Theileria parva lawrencei sporozoites derived from an African buffalo and treatment with buparvaquone. Parasitology 96, 391-402.

Mwangala F (1997) Effect of Ububa (Tephrosia vogelli) water extracts on Rhipicephalus appendiculatus nymphae. An International Scientific Symposium Organised in Commemoration of the 10th Anniversary of The Opening of The Samora Machel School of Veterinary Medicine, 9-11th April 1997, Lusaka, Zambia.

Nambota A (1991) Immunisation against Theileriosis in the Southern Province of Zambia. In Proceedings of a Workshop on East Coast Fever Immunisation, Lilongwe, Malawi 20-22 September 1988 (ed. TT Dolan), pp. 87-89.

Norval RAI, Sutherst RW, Kurki J, Gidson JD \& Kerr JD (1988) The effect of the brown-ear tick Rhipicephalus appendiculatus on the growth of Sanga and European breed cattle. Veterinary Parasitology 30, 149-164.

Norval RAI, Sutherst RW, Jorgensen OG, Gibson JD \& Kerr JD (1989) The effect of the bont tick (Amblyomma hebraeum) on the weight gain of Africander steers. Veterinary Parasitology 33, 329-341.

Norval RAI, Sutherst RW, Kurki J, Kerr JD, Gibson JD (1990a) The effects of the brown ear-tick Rhipicephalus appendiculatus on milk production of Sanga Cattle. In Tick Vector Biology, Medical and Veterinary Aspects (ed. B Fivaz et al.) Springer-Verlag, London, pp. 35-54.

Norval RAI, Sutherst RW, Jorgensen OG, Kerr JD (1990b) The effects of the bont tick (Amblyomma hebraeum) on milk production of Sanga and Sanga X Brahman cattle. In Tick Vector Biology, Medical and Veterinary Aspects (ed. B Fivaz et al.) SpringerVerlag, London, pp. 35-54.

Norval RAI, Barrett JC, Perry BD, Mukhebi AW (1992a) Economics, Epidemiology and Ecology: A multidisciplinary Approach to the 


\section{D'Haese et al. Epidemiology and control of bovine theileriosis}

Planning and Appraisal of Tick and Tick-Borne Disease Control in Southern Africa. In Tick Vector Biology, Medical and Veterinary Aspects (ed. B Fivaz et al.) Springer-Verlag, London, pp. $35-54$.

Norval RAI, Perry BD \& Young AS (1992b) The Epidemiology of Theileriosis in Africa. Academic Press Limited, London, pp. 481.

Okamoto M (1993) Traditional Medicines for Cattle disease. In 6th General Conference of the Mazabuka Traditional Farm Development Project November 25, 1993, Department of Veterinary and Tsetse Control Services, Japan Overseas Volunteers under Japan International Co-operation Agency, pp. 32-34.

Pegram RG, Lemche J, Chizyuka HGB et al. (1989) Effects of tick control on live weight gain of cattle in central Zambia. Veterinary and Medical Entomology 3, 313-320.

Pegram RG, James AD, Oosterwijk GPM et al. (1991) Studies on the economics of ticks in Zambia. Experimental and Applied Acarology 12, 9-26.

Penne KLG, Elyn RND \& D'Haese L (1996) Economics of cattle keeping, ECF and Trypanosomosis Control in the ASVEZA Project of Zambia. Internal document ASVEZA-Project, pp. 158.

Penne KLG \& D'Haese L (1997) Theileriosis control modelling. Presentation for the International Colloquium on Epidemiology and Control of Bovine Theileriosis, Institute of Tropical Medicine, Antwerp, Belgium. 10-12 December, 1997.

Perry BD, Curry JJ \& Mukhebi AW (1991) Assessment of the impact of control measures against Theileriosis. In Ticks and Tick-borne disease control, proceedings of a joint OAU, FAO and ILRAD workshop held in Kampala, Uganda, 12-14 September 1991 (ed. TT Dolan), pp. 32-34.

Radley DE (1981) Infection and treatment immunisation against Theileriosis. In Advances in the Control of Theileriosis: Proceedings of an international Conference Held at ILRAD, Nairobi, 9-13 February 1981 (ed. AD Irwin et al.), Martinus Nijhoff Publishers, The Hague, pp. 227-236.

Rumberia RM, Eley RM, Young AS \& Watson ED (1993) The effect of high and low dose Theileria parva infection on the reproductive function of Boran/Friesian cross heifers. Theriogenology 40, 977-986.

Rumberia RM, Rowland AC, Watson ED, Eley RM \& Young AS (1994) The effect of immunisation against Theileriosis on the reproductive function of Boran/Friesian cross heifers - A preliminary Study. British Veterinary Journal 150, 301-303. Speybroeck N (1994) Tick Report 1993-94. Internal Report ASVEZA-Project, Belgian co-operation in Zambia, Ministry of Agriculture, Food and Fisheries.

Van Doorslaer B (1996) Produktie en Marketing van Melk in Chipata-Distrikt (Zambia). Scriptie voorgedragen tot het behalen van de graad van Bio-Ingenieur in de Landbouwkunde, Universiteit Gent, Faculteit Landbouwkundige en Toegepaste Biologische Wetenschappen, pp. 86.

\section{Appendix I}

Summary of factors influencing total economic cost

\begin{tabular}{|c|c|c|c|c|c|}
\hline & \multicolumn{2}{|l|}{ Productivity losses } & \multicolumn{3}{|c|}{ Expenditures } \\
\hline & TBD -Effects & Tick loads & Fixed costs & Variable costs & \\
\hline & Mortality & Morbidity & & & \\
\hline No intervention & $\begin{array}{l}\text { Both f (Occurrence) } \\
\text { Mortality } \\
\text { /morbidity }=\mathrm{f}(\mathrm{CF})\end{array}$ & $\begin{array}{l}\text { Presence of ticks can } \\
\text { result in significant } \\
\text { production losses }\end{array}$ & - & - & \\
\hline Treatment & Reduced (CF increased $95->20 \%$ ) & $\begin{array}{l}\text { Presence of ticks can } \\
\text { result in significant } \\
\text { production losses }\end{array}$ & $\begin{array}{l}\text { Research } \\
\text { Drug delivery system }\end{array}$ & $\begin{array}{l}\text { Drugs } \\
\text { Professional fees } \\
\text { Farm labour cost } \\
\text { Transport }\end{array}$ & \\
\hline Vector control & Strongly reduced & Strongly reduced & Strongly reduced & $\begin{array}{l}\text { Research } \\
\text { F(control method) }\end{array}$ & $\begin{array}{l}\text { Acaricide } \\
\text { Transport } \\
\text { Labour }\end{array}$ \\
\hline Immunization & Strongly reduced & $\begin{array}{l}\text { Immunization might } \\
\text { result in limited } \\
\text { productivity loss }\end{array}$ & $\begin{array}{l}\text { Presence of ticks } \\
\text { can result in significant } \\
\text { production losses }\end{array}$ & $\begin{array}{l}\text { Research } \\
\text { Storage } \\
\text { Production unit }\end{array}$ & $\begin{array}{l}\text { Vaccine } \\
\text { Transport } \\
\text { Labour } \\
\text { Professional fees }\end{array}$ \\
\hline
\end{tabular}

